\title{
Constraining tectonic components during a geomechanics-aided successful hydrofracturing campaign of tight gas exploration field
}

\author{
Rajeev Ranjan Kumar ${ }^{1} \cdot$ Menno Mathieu Molenaar $^{2} \cdot$ Surej Kumar Subbiah ${ }^{1}$
}

Received: 11 October 2021 / Accepted: 2 November 2021 / Published online: 20 November 2021

(c) The Author(s) 2021

\begin{abstract}
The horizontal stress profile plays an important role, extending from wellbore stability analysis to well completion optimization of tight gas reservoirs. When considering exploration fields with planned wells being drilled to 5500-m TVD, it is imperative to quantify tectonic effects at the well location. In addition, accurately predicting stress profile and fracture initiation values in vertical wells is required to identify sweet zones and barriers. This paper presents the details of a prefracture geomechanical model using breakouts and advanced acoustic data for post-fracture analysis. The analysis contains a history match of fracture initiation pressure, which consider the effects of filter cake around permeable sand, variation in tensile strength, and quantification of horizontal stress contrast in the different fields. Overall, three reservoirs have been analyzed, each containing more than eight wells with operations history. Core tests were used to calibrate dynamic-to-static rock elastic and mechanical properties, both of which reduced uncertainty in the model. The poroelastic horizontal strain method was used to build a continuous stress profile. Typically, the rock fabric found in the cores, images, and anisotropy data from the three reservoirs is different and required various dynamic-to static conversions. The Aeolian deposits-based reservoir has a wide variation in horizontal stress, and fracture height is typically governed by the stiffness of the layers. The lower permeability zones have relatively higher tensile strength, compared with higher permeability zones leading to relatively higher fracture initiation values. Overall, the ratio of maximum horizontal stress-to-minimum horizontal stress varies between 1.20 and 1.28 based on post-fracture analysis, which correlates well with regional tectonics and structural data. Depending on lithological variation and structure changes, the horizontal strain component varies at the layer level within regional tectonics. Inversion of fracturing data helped to constrain horizontal strain and stress variations in the field.
\end{abstract}

Keywords Breakdown $\cdot$ Closure pressure $\cdot$ Facies $\cdot$ Stress profile

\begin{tabular}{|c|c|c|c|}
\hline \multicolumn{3}{|c|}{ Abbreviations } & E dyn \\
\hline \multicolumn{2}{|c|}{ Alpha } & Biot's effective stress constant & PHIT/POR \\
\hline \multicolumn{2}{|c|}{ E_Sta } & Static Young's modulus & CQ \\
\hline \multicolumn{2}{|c|}{ Pr_Sta } & Static Poisson's ratio & MW \\
\hline \multicolumn{2}{|c|}{ SHMIN } & Minimum horizontal stress & MEM \\
\hline \multicolumn{2}{|c|}{ SHMAX } & Maximum horizontal stress & BDP \\
\hline \multicolumn{2}{|c|}{ SVERTICAL } & Vertical stress & $\mathrm{CP}$ \\
\hline \multicolumn{2}{|c|}{ TSTR } & Tensile strength & RHOZ / DEN \\
\hline \multirow[t]{3}{*}{$\triangle$} & \multicolumn{2}{|c|}{$\begin{array}{l}\text { Rajeev Ranjan Kumar } \\
\text { rajeev_iit2@yahoo.co.in }\end{array}$} & $\begin{array}{l}\text { Pw } \\
\text { Ex }\end{array}$ \\
\hline & \multicolumn{2}{|c|}{$\begin{array}{l}\text { Menno Mathieu Molenaar } \\
\text { mathieu.molenaar@shell.com }\end{array}$} & Ey \\
\hline & \multicolumn{2}{|c|}{ SSubbiah@slb.com } & GRTL1 \\
\hline \multicolumn{3}{|c|}{ Schlumberger, Houston, USA } & \\
\hline \multicolumn{3}{|c|}{ Shell, The H } & \\
\hline
\end{tabular}

Dynamic Young's modulus

Total porosity

Completion quality

Mud weight

Mechanical earth model

Breakdown pressure

Closure pressure

Bulk density

Thermal neutron porosity

Gamma ray

Fracture width

Strain at minimum horizontal stress direction

Strain at maximum horizontal stress direction Gamma Ray post-frac using tracer $\log$

Shell, The Hague, Netherlands 


\section{BF_SWBO_Image Predicted wide breakouts using 1D MEM}

CALI Hole size using caliper measurement

\section{Introduction}

To enhance gas production, hydrofracturing operations were conducted across multiple tight sandstone reservoirs. The hydraulic fracturing process involves rock in which the downhole fluid pressure exceeds the minimum principal stress plus the tensile strength. These conditions result in tensile failure of the rock. Continued pumping at higher pressures causes the rock layer to split and the induced fracture will grow in the direction of least resistance, i.e., the maximum horizontal stress azimuth where hoop stress is minimum.

To optimize hydrofracturing operations and avoid unexpected issues with additional costs, it is essential to understand closure pressure, fracture initiation pressure, and stiffness values across the target sandstone layers and nearby fracture-height barrier layers (Spain et.al. 2015). This knowledge assists in designing the proppant and operation size. These geomechanical parameters are estimated using a 1D mechanical earth model (MEM) process involving sonic dipole data, borehole images, caliper, and openhole logs. Available rock mechanics core laboratory test data are used for additional calibration. Recent works (Salim et al. 2021 and Gondalia et al. 2019) show clearly the value addition of geomechanics in successful hydrofracturing design.

The present investigation involves geomechanical analysis of three target sandstone reservoirs in different wells where pre-fracture and post-fracture results on closure pressure and fracture initiation pressure were compared. Actual post-fracture results were used to estimate tectonic horizontal strains at different well locations in the field and map local variations. The post-fracture-height measurements and pressure history match were used to calibrate the stress profile and tensile strength. This calibration also provides confidence in the pre-job modeling workflow and the results for future wells in the field.

\section{Geology}

Target sandstone reservoirs located in the complex depositional system under review vary from continental deposits to shallow marine transition systems. The presence of faults often induces variation in the local tectonics with changes in stress azimuth and magnitude. These faults belong to the Cambrian to Lower Silurian Haima Supergroup. Facies in each reservoir show lateral variation in terms of petrophysical parameters with changes in microstructure. Anisotropy data correlate well with geological features, providing confidence in mapping these variations in the wells. Brief descriptions of each target reservoir are summarized in Table 1.

\section{Pre-fracture geomechanical model}

In this study, a poroelastic horizontal strain model (Fjaer et al. 1992) was used to estimate the magnitudes of the minimum and maximum horizontal stresses. This technique does not predetermine or preconceive the order of the in situ stresses. Instead, the technique allows for convergence in the estimates of stress magnitudes; hence, stress regimes that are driven by the available log and well data.

The method applies poroelastic theory to the long-term sedimentation and deposition of formations buried deep below the earth's surface. This method accounts for lateral spreading or horizontal compression or both by strains that might occur in the horizontal $\mathrm{x}$ and $\mathrm{y}$ directions. Hence, the two strains, $E_{x}$ (in the minimum horizontal stress direction) and $E_{y}$ (in the maximum horizontal stress direction), can be used as calibration factors to match the stress model to the current state of stress in the earth. Applying this approach, we obtain values using Eq. 1 and Eq. 2 as follows:

$$
\begin{gathered}
\sigma_{h}=\frac{v}{1-v} \sigma_{v}-\frac{v}{1-v} \alpha P_{p}+\alpha P_{p}+\frac{E}{1-v^{2}} e_{x}+\frac{v E}{1-v^{2}} e_{y} \\
\sigma_{H}=\frac{v}{1-v} \sigma_{v}-\frac{v}{1-v} \alpha P_{p}+\alpha P_{p}+\frac{E}{1-v^{2}} e_{y}+\frac{v E}{1-v^{2}} e_{x}
\end{gathered}
$$

Table 1 Target reservoir descriptions

\begin{tabular}{ll}
\hline Target Reservoir & Descriptions \\
\hline Res 1 & $\begin{array}{c}\text { Cambrian facies, at the lower most portion of the Haima Supergroup, deposited by braided fluvial systems, but feature a } \\
\text { significant amount of reworking in the Aeolian and dry sabkha environments in its upper portions }\end{array}$ \\
Res 2 & $\begin{array}{l}\text { Middle Cambrian, Haima Supergroup, deposited in alluvial and playa and lacustrine to sabkha environments with minor } \\
\text { Aeolian intervals }\end{array}$ \\
Res 3 & Late Cambrian-Early Ordovician siliciclastic sediments of the Andam formation, deposited along a ramp-type low-relief basin
\end{tabular}


where $\sigma \mathrm{h}=$ minimum horizontal stress, $\sigma \mathrm{H}=$ maximum horizontal stress, $\sigma \mathrm{V}=$ vertical stress, $\alpha=$ Biot elastic coefficient, $\mathrm{Pp}=$ pore pressure, $\mathrm{E}=$ static Young's Modulus, $\mathrm{v}=$ static Poisson's ratio, $E_{x}=$ strain at minimum horizontal stress direction, and $E_{y}=$ strain at maximum horizontal stress direction, respectively. This algorithm assumes that the principal stresses are aligned perfectly with the vertical axis, and the minimum and maximum horizontal stress profiles have no inclined stress.

Vertical stress was estimated using density data. Direct formation pressure measurements suggest a range of 0.49 $\mathrm{psi} / \mathrm{ft}$ to $0.54 \mathrm{psi} / \mathrm{ft}$ in the different target reservoirs. To estimate the static Young's modulus and Poisson's ratio, calculated dynamic values were obtained using standard equations (Fjaer et al. 1992) based on openhole logs transformed built on the core data. For target Reservoir 3 (Res 3), the following equations (Eq. 3 and Eq. 4) were used for reference as follows:

$E=1.1 \times E_{d y n}-4.1301$ $v=0.5 \times P R_{d y n}+0.08$

These calculations are performed under 1D mechanical earth model construction to history match field observations (Plumb et.al. 2000, Lei et.al. 2012). A typical ratio of the maximum to the minimum horizontal stress ratio ranges from 1.18 to 1.25 . Based on the predrill model, estimated closure pressure ranged from 10,300 psi to 19,000 psi for the wells in this study. Breakdown pressure (the fracture initiation pressure) can be calculated based on either model, i.e., the impermeable borehole wall with the fast pressurization case or the porous wall with the slow pressurization case. In this study, the fast pressurization model was used with Eq. 5 for the upper limit with the assumption of perfect mud cake.

Breakdown pressure $=3 * \sigma_{h}-\sigma_{h}+$ TSTR $-P_{p}$

With the lower mud cake thickness, breakdown pressure also decreased depending on the poroelastic stress coefficient. A few of the fracture stages were run after deep perforations were made in very tight fabrics where

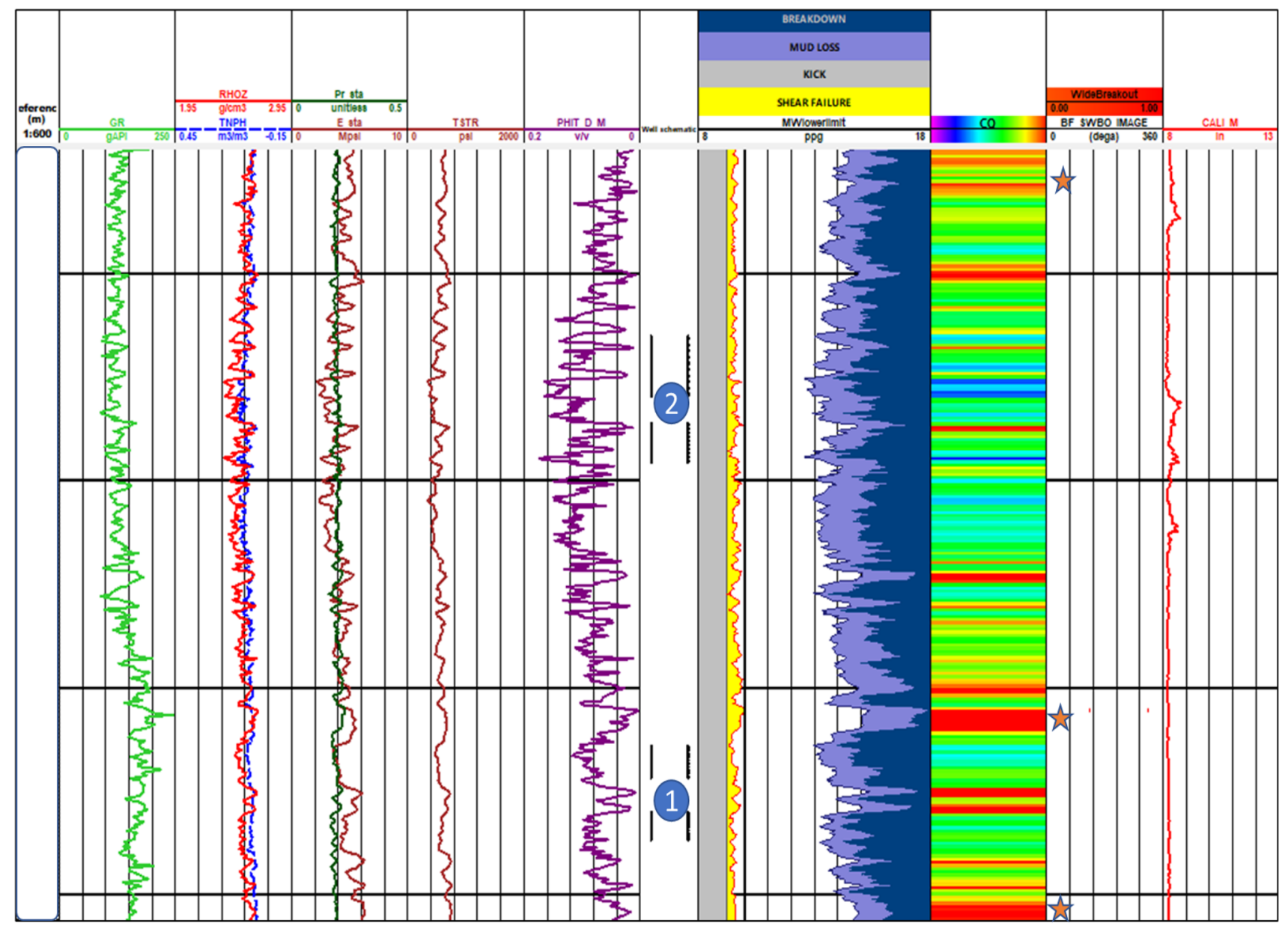

Fig.1 Pre-fracture 1D MEM for Well-1 in Res 2 


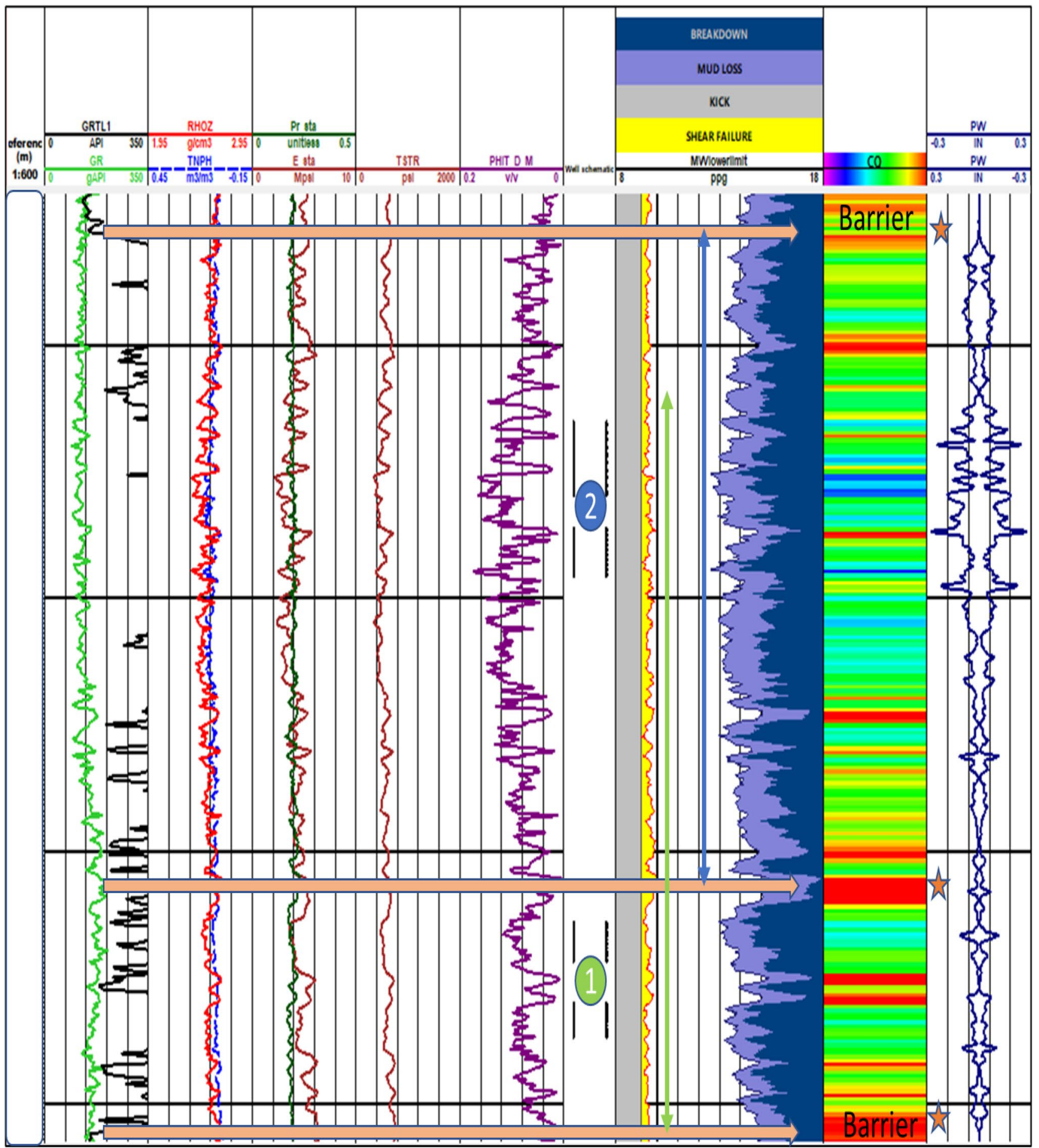

Fig. 2 1D MEM for Well-1 with tracer data

the breakdown values were reduced by $600 \mathrm{psi}$ to $900 \mathrm{psi}$ in Res 3. In such cases, the thickness of the mud filter cake was considered for calculations (Fjaer et al. 1992).

Figure 1 shows the pre-fracture MEM with proposed stages in Res 2 based on petrophysical and geomechanical parameters. Fracture-height barriers for Well-1 were identified based on the completion quality, which represents the minimum horizontal stress gradient. 


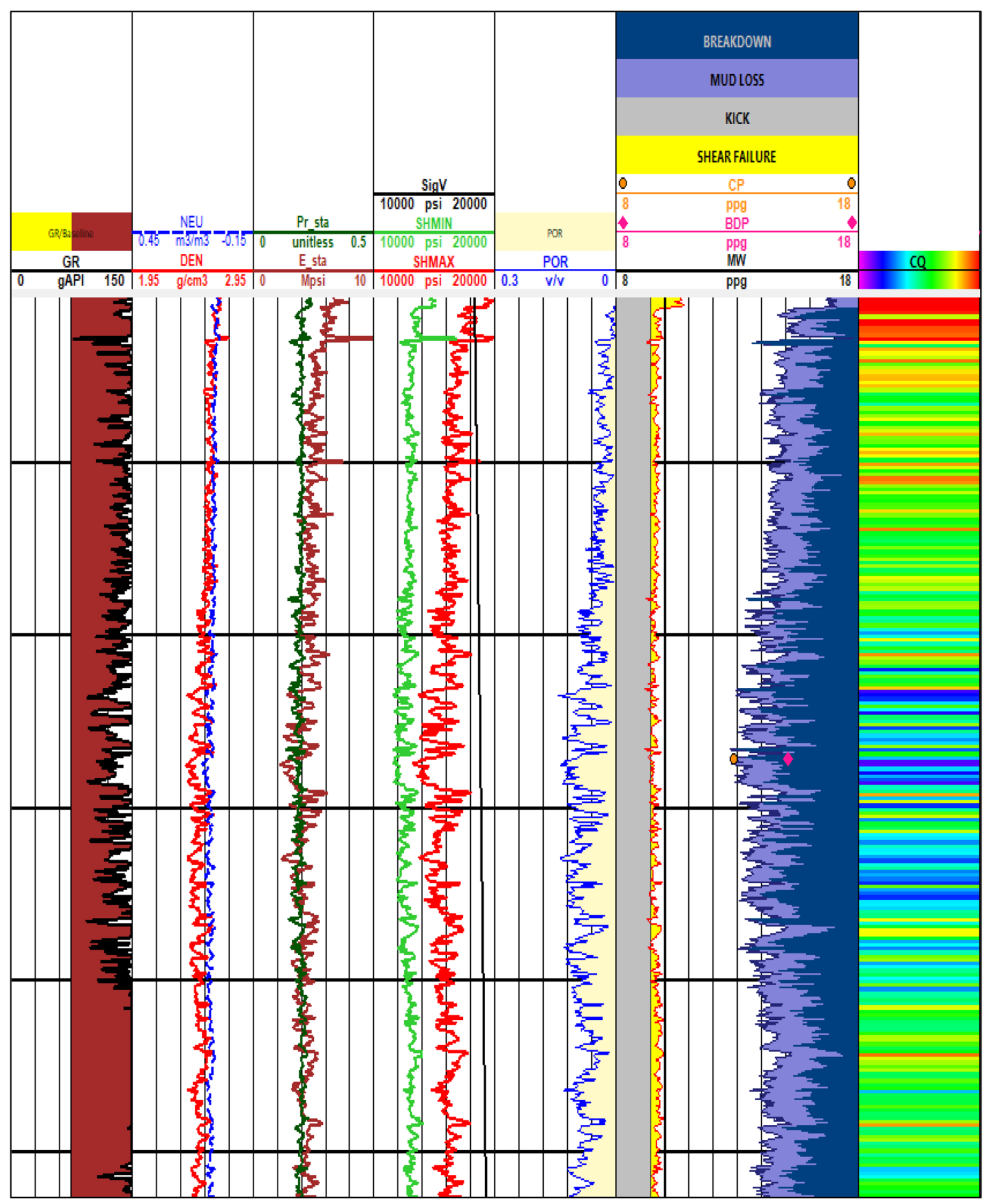

Fig. 3 1D MEM for Well-4 with actual frac data

\section{Post-fracture geomechanical model review}

Post-fracture tracer analysis indicated major stress barriers at the top and bottom of reservoir as predicted by the MEM, with the thin intermediate barrier at the top boundary of the proposed first stage (Fig. 2). Fracture width matches well with the completion quality. Fracture height for both stages, indicated by the appropriate color, shows fracture-height growth beyond the intermediate barrier during the first stage. Upon reviewing pressure vs. 
Table 2 Actual vs. predicted closure pressure values across multiple wells

\begin{tabular}{lllll}
\hline Well Name & Frac stages & Predicted CP & Actual CP & Delta CP \% \\
\hline Well-1 & Stage-1 & 11,370 & 11,400 & 0.26 \\
& Stage-2 & 11,450 & 11,535 & 0.74 \\
Well-2 & Stage-1 & 11,631 & 11,953 & 2.70 \\
& Stage-2 & 11,637 & 10,986 & 5.93 \\
Well-3 & Stage-1 & 11,458 & 11,235 & 1.98 \\
& Stage-2 & 10,994 & 10,886 & 0.99 \\
Well-4 & Stage-3 & 11,461 & 11,342 & 1.05 \\
& Stage-1 & 11,908 & 11,586 & 2.78 \\
Well-5 & Stage-1 & 11,286 & 11,216 & 0.62 \\
& Stage-2 & 12,209 & 11,796 & 3.50 \\
\hline
\end{tabular}

time data, it was found that there was a sudden pressure loss. This loss could be due to channeling effects beyond the formation and height growth rather than greater width growth as confirmed by tracer data. Predicted closure pressure values for both stages match within a range of $1 \%$ of actual closure pressure values. Overall, two stages were conducted, which covered the entire package (Res 2) vs. conventional five or six stages in nearby development fields.
A similar comparison has been performed for other wells across Res- 2 where Delta\% is within $5 \%$ of actual values. Results for Well-4 are shown in Fig. 3, where actual closure pressure (CP) and breakdown pressure gradient (BDP) are plotted against predicted values. Different fracturing stages results across multiple wells are mentioned in Table 2.

To assess actual tectonic stress heterogeneity across the field, fracture variation based on breakdown pressure was captured along with the tensile strength. These data were used to calculate the maximum horizontal stress and compare it with predicted values using the 1D MEM. Actual values from the different reservoirs are shown in Fig. 4. Overall, as the in situ stress profile state increases, relative increase in breakdown pressure decreases at higher horizontal stress values. Res 2 shows much less variation, while Res 3 exhibits wide variations. The geological variation in terms of cross-bedded sandstone and clay sheet for Res 3 causes the wide variations. Most of the borehole breakouts occur along the clay sheet that is present in Res 3. General trend for Res-1 and Res-3 shows higher level of variation of elastic properties and rock quality resulting in wide variation in closure pressure and breakdown pressure values.

(BREAKDOWN PRESSURE VS CLOSURE PRESSURE)

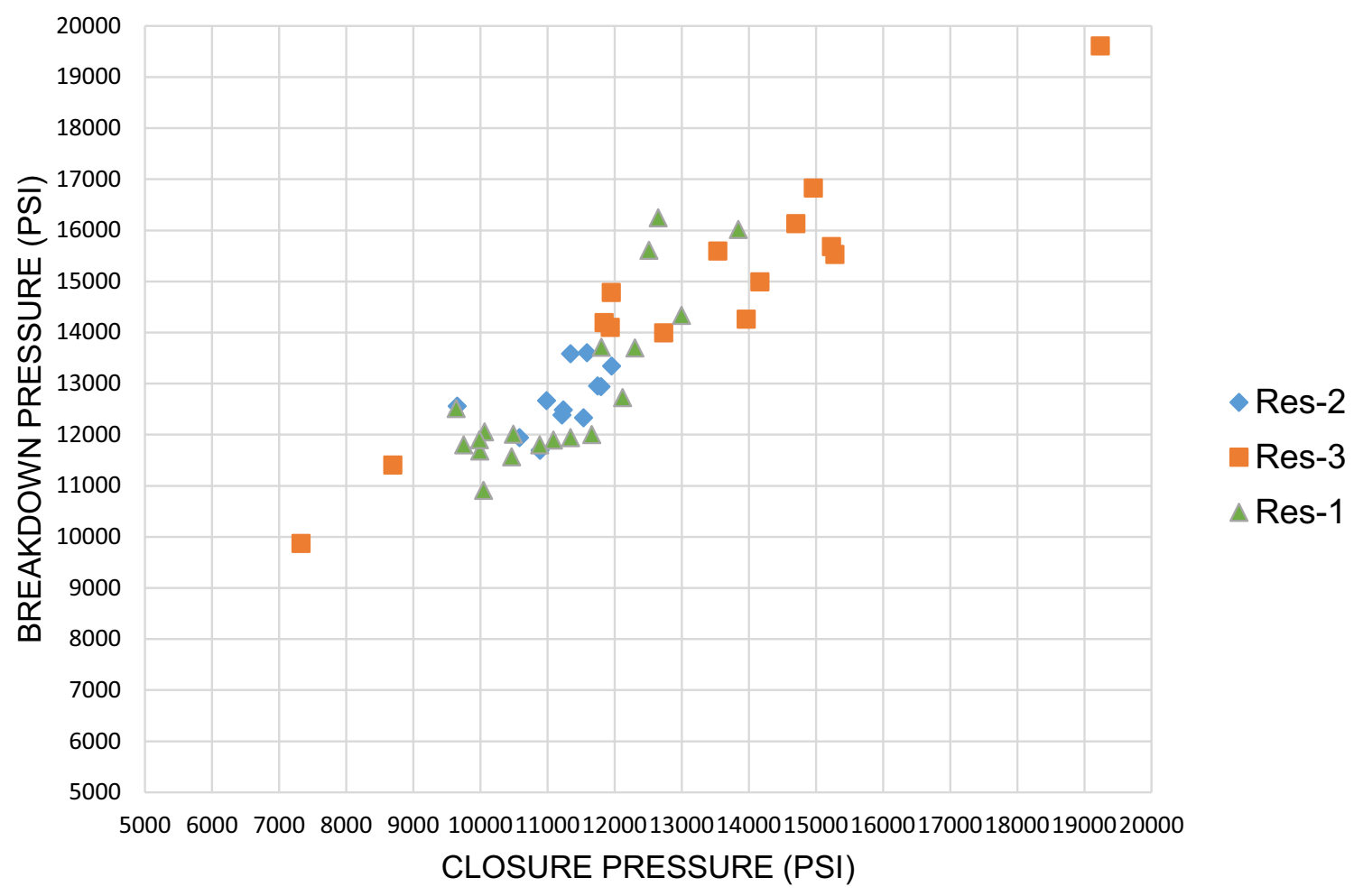

Fig. 4 Breakdown and closure pressure values from hydrofracturing operations 


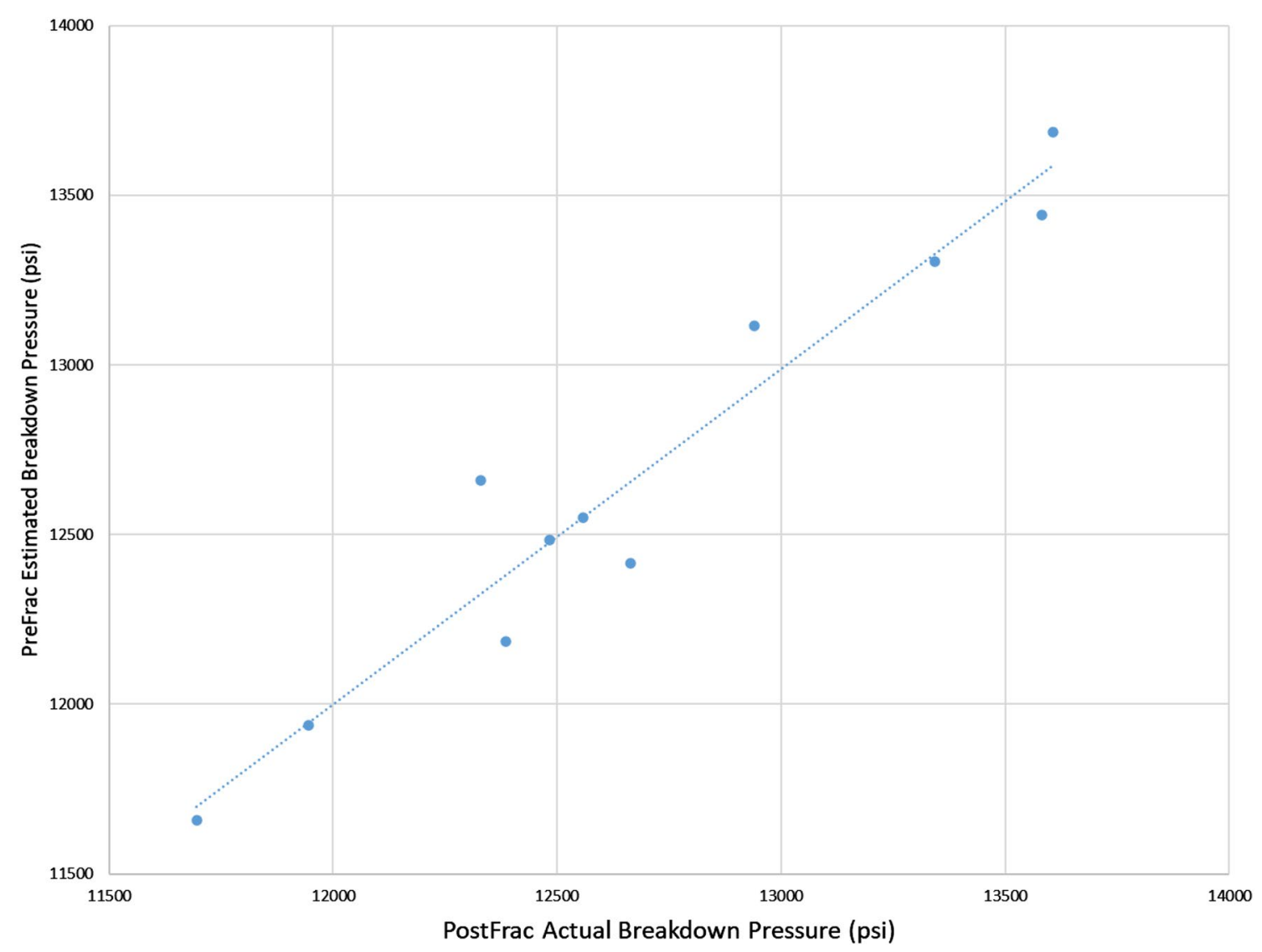

Fig. 5 Modeled vs. actual breakdown pressure values from hydrofracturing operations

Fig. 6 Stress ratio vs. closure pressure (psi)
Stress Ratio vs. CP

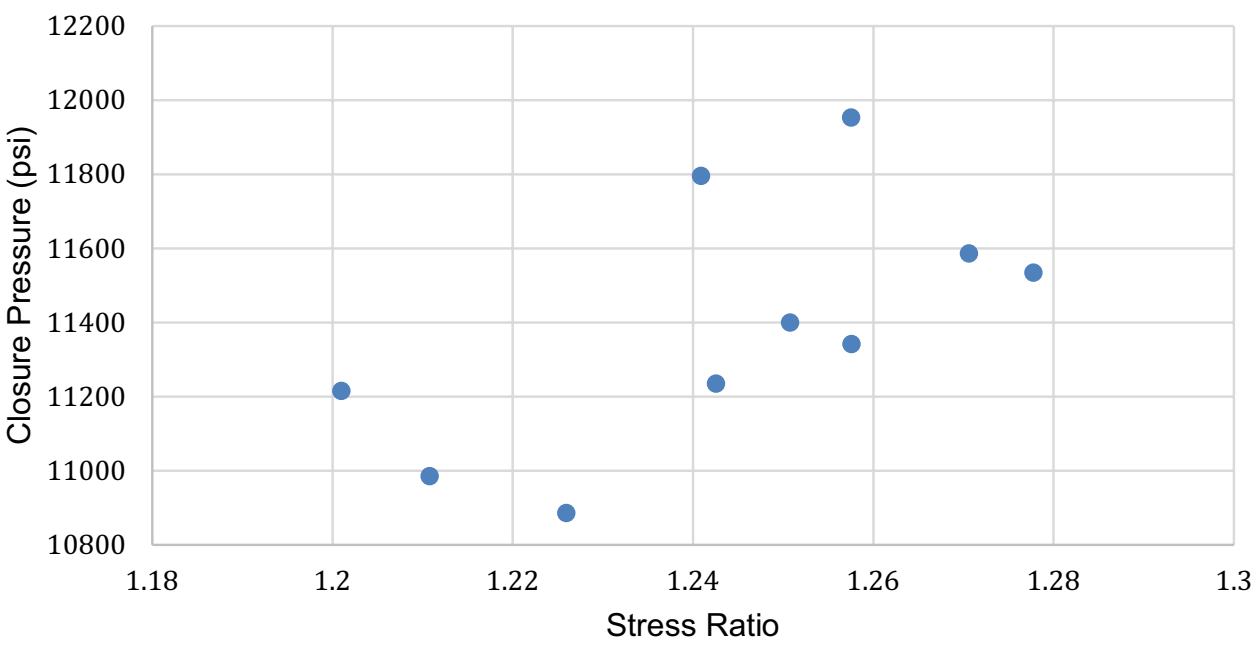

Considering slow pressurization model, estimated breakdown pressure values are close to actual breakdown pressure values for Res-2 as seen in Fig. 5. The calculated maximum horizontal stress using fracture data indicates the stress ratio ( $\mathrm{max} / \mathrm{min}$ horizontal stress) to range between 1.20 and 1.28 for Res-2 (Fig. 6). The tensile strength, based on fracture data (breakdown pressure-reopening pressure), appears to be different than core 
calibrated log-based values by $10 \%$ to $15 \%$; hence, there might be corresponding uncertainty in the stress ratio. However, even with quantified uncertainty, the analysis suggests that the field under study is showing significant variation in the stress magnitude. Wells with a higher stress ratio have relatively higher stiff rock fabric with medium petrophysical and reservoir facies.

Finally, inversion of fracturing data from different reservoir sets with help of Eqs. (1) and (2) gives $E_{x}$ and $E_{y}$ to vary between $0.20-0.25$ and $1.00-1.10$, respectively. This clearly shows the field with minimum variation of tectonic horizontal strains along one axis across the field.

\section{Summary}

An integrated workflow to understand stress variation across a field has been developed by coupling petrophysical, geological, and geomechanical methods using well logs and actual hydrofracturing jobs performed in the field. The stress ratio appears to have a wide variation, which corresponds to rock facies across the different reservoirs.

The study shows that the height and width of hydraulic fractures are strongly controlled by the rock stiffness and the minimum horizontal stress. Predrill models are extremely useful for perforation design and key fracture jobs with a minimum deviation of $2 \%$ from the actual values for Res 2 . The results aid in understanding the rock properties that vary in each reservoir. The study also helped to confirm the minimum stages required to cover each reservoir across the field with a more robust geomechanical model. The key factor in wide variations of closure and breakdown pressure values are elastic properties and pore pressure.

Acknowledgements The authors would like to thank Schlumberger and Shell for providing extensive support for the planning, development, and execution of the project and for work publication.

Author contribution Rajeev Ranjan Kumar and Menno Mathieu Molenaar contributed on acquisition of data, conception and framework, while Surej Kumar Subbiah helped on peer review of interpretation of data and provided critical feedback for finalization of content during revised submission.

Funding The authors have no relevant financial or non-financial interests to disclose. The authors have no financial or proprietary interests in any material discussed in this article. All authors certify that they have no affiliations with or involvement in any organization or entity with any financial interest or non-financial interest in the subject matter or materials discussed in this manuscript.
Conflicts of interest The authors have no conflicts of interest to declare that are relevant to the content of this article.

Open Access This article is licensed under a Creative Commons Attribution 4.0 International License, which permits use, sharing, adaptation, distribution and reproduction in any medium or format, as long as you give appropriate credit to the original author(s) and the source, provide a link to the Creative Commons licence, and indicate if changes were made. The images or other third party material in this article are included in the article's Creative Commons licence, unless indicated otherwise in a credit line to the material. If material is not included in the article's Creative Commons licence and your intended use is not permitted by statutory regulation or exceeds the permitted use, you will need to obtain permission directly from the copyright holder. To view a copy of this licence, visit http://creativecommons.org/licenses/by/4.0/.

\section{References}

Al-Busaidi, Salim, Hinaai, Qasim, Kumar, Rajeev Ranjan, Chen, Ying Ru, Al Lawatia, Redha Hasan, Yu, Dai Guo, Singh, Amit Kumar, and Surej Kumar Subbiah (2021) Successful drilling campaign of high angled wells in tight gas fields using $3 \mathrm{~d}$ geomechanical modeling and real-time monitoring. SPE. 202123. https://doi.org/10.2118/202123-MS.

Fjaer E, Horsrud P, Raaen AM, Risnes R, Holt R. M (1992) Petroleum Related Rock Mechanics Developments in Petroleum Science 33 Elsevier 1992. https://www.elsevier.com/books/petro leum-related-rock-mechanics/fjaer/978-0-444-88913-3.

Gondalia, Ravi Ramniklal, Kumar, Rajeev Ranjan, Zacharia, Joseph, Shetty, Varun , Bandyopadhyay, Atanu, Narayan, Shashank , Bordeori, Krishna, Singh, Mukund Murari, Shah, Arpit, Choudhary, Dinesh, Sharma, Lovely, Ray, Maria Fernandes, Sarkar, Samarpita, Moulali, Shaik , Das, Santanu , and Dasari Papa Rao. 2019. Fracturing fluid and geomechanics integration solves hydraulic fracturing in the HP/HT triassic - jurassic petroleum system, Krishna Godavari Basin, India. SPE. 196357. https://doi. org/10.2118/196357-MS

Lei T, Sinha BK, Sanders M (2012) Estimation of horizontal stress magnitudes and stress coefficients of velocities using borehole sonic data. Geophysics. 77(3): 1MJ-Z74 May. https://doi.org/10. 1190/geo2011-0277.1

Plumb, Richard, Edwards, Stephen, Pidcock, Gary, Lee, Donald, and Brian Stacey (2000) The mechanical earth model concept and its application to high-risk well construction projects. In: Presented at the IADC/SPE Drilling Conference, New Orleans, Louisiana, USA, 23-25 February. SPE-59128-MS. https://doi.org/10.2118/ 59128-MS

David R. Spain, Raja Naidu, William Dawson, German D. Merletti, Rajeev Kumar, Dai Yu Guo (2015) Integrated Workflow for Selecting Hydraulic Fracture Initiation Points in the Khazzan Giant Tight Gas Field, Sultanate of Oman. SPE 177939. https:// doi.org/10.2118/177939-MS

Publisher's Note Springer Nature remains neutral with regard to jurisdictional claims in published maps and institutional affiliations.

\section{Declaration}

